
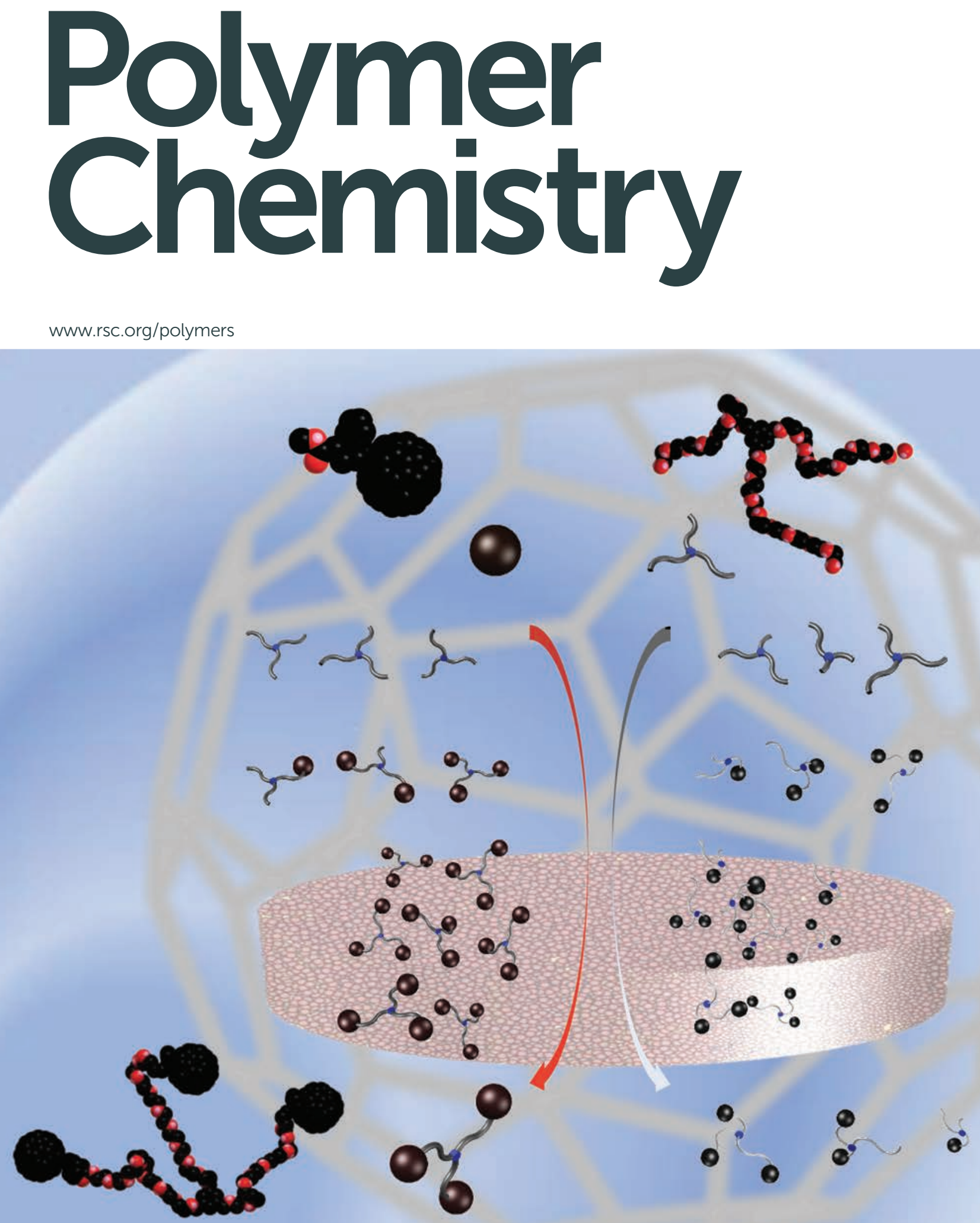

ISSN 1759-9954

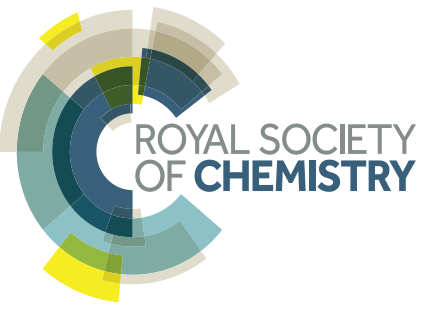




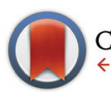

CrossMark \&lick for updates

Cite this: Polym. Chem., 2015, 6 , 1056

Received 22nd August 2014 Accepted 7th November 2014

DOI: $10.1039 / c 4 p y 01167 h$

www.rsc.org/polymers

\title{
Synthesis and characterization of branched fullerene-terminated poly(ethylene glycol)s $\uparrow$
}

\author{
Hin Chun Yau, $\neq^{\mathrm{a}}$ Mustafa K. Bayazit, $\$^{\mathrm{b}}$ Piers R. J. Gaffney, ${ }^{\mathrm{c}}$ Andrew G. Livingston, ${ }^{\mathrm{C}}$ \\ Joachim H. G. Steinke and Milo S. P. Shaffer*a
}

\begin{abstract}
Poly(ethylene glycol) [1, PEG $\sim 4(\mathrm{OH})_{2}, M_{\mathrm{n}} \sim$ 200], glycerol ethoxylate [2, PEG ${ }_{\sim 21}(\mathrm{OH})_{3}, M_{\mathrm{n}} \sim 1000$ ] and pentaerythritol ethoxylate [3, $\mathrm{PEG}_{\sim 15}(\mathrm{OH})_{4}, M_{\mathrm{n}} \sim 797$ ] react directly with phenyl- $\mathrm{C}_{61}$-butyric acid methyl ester (PCBM), in the presence of dibutyltinoxide (DBTO) catalyst at $140{ }^{\circ} \mathrm{C}$, to give a mixture of fullerene $\left[\mathrm{C}_{60}\right]$ end-capped PEGs via transesterification. Among these PEG linkers, only PEG ${ }_{\sim 4}(\mathrm{OPCB})_{2}(4 a)(\mathrm{OPCB}$ : ester oxygen linked phenyl- $C_{61}$-butyryl group) was successfully isolated from the crude product mixture in the fully end-capped form. Fully acylated $\mathrm{PEG}_{\sim 21}(\mathrm{OPCB})_{3}(5)$ and $\mathrm{PEG}_{\sim 15}(\mathrm{OPCB})_{4}(\mathbf{6})$ could not be separated chromatographically from incompletely reacted species due to the polydispersity in branch lengths. This purification challenge was overcome by using a monodisperse branched core, 1,3,5-tris(octagoloxymethyl)benzene [7, $\left.\mathrm{PEG}_{24}(\mathrm{OH})_{3}\right]$ to give a monodisperse tris-fullerene homostar, $\mathrm{PEG}_{24}(\mathrm{OPCB})_{3}(\mathbf{8})$. The structures of the bis- and tris-fullerene products were confirmed by MALDI-TOF mass spectrometry and ${ }^{1} \mathrm{H}$ NMR spectroscopy with supporting FTIR and UV-vis spectroscopic analysis.
\end{abstract}

\section{Introduction}

Due to its unique optoelectronic properties, and phase behaviour, fullerene[60] is one of the most commonly used materials in the preparation of polymer donor-acceptor bulk heterojunction (BHJ) solar cells. ${ }^{1-4}$ However, the low solubility and processability of fullerenes in organic solvents has limited their direct use in solution and encouraged the development of a wide range of functionalised derivatives, including methanofullerenes ${ }^{5-9}$ and fulleropyrrolidines. ${ }^{10,11}$ These functionalised derivatives offer significant increases in solubility and processability while preserving the important electronic and optical properties of the parent fullerenes. Direct functionalization of fullerenes is a simple option to prepare derivatives; however, multiple addition may occur which can affect optoelectronic properties. Phenyl- $\mathrm{C}_{61}$-butyric-acidmethyl-ester (PCBM) has received considerable attention in solution-processed organic electronic applications, particularly for electron transport in solar cells. ${ }^{12}$ As a result, this material

\footnotetext{
${ }^{a}$ Department of Chemistry, South Kensington Campus, Imperial College London, London, SW7 2AZ, UK. E-mail: m.shaffer@imperial.ac.uk

${ }^{b}$ Department of Chemical Engineering, University College London, London, WC1E $7 J E, U K$

${ }^{c}$ Department of Chemical Engineering, South Kensington Campus, Imperial College London, London, SW7 2AZ, UK

$\dagger$ Electronic supplementary information (ESI) available: NMR spectra, and MALDI-TOF spectra of the polydisperse multifullerene PEG adducts. See DOI: 10.1039/c4py01167h

$\$$ These authors contributed equally to this work.
}

is readily available commercially, and offers a convenient reagent for the preparation of monofunctionalized fullerene derivatives via transesterification of its methyl ester functional group. ${ }^{8,13,14}$

The performance of fullerene-polymer based bulk heterojunction (BHJ) solar cells depends on the characteristic lengthscale and crystallinity of the thin, phase-segregated semiconductor active layer; ${ }^{15-19}$ this structure is controlled by the dynamics of the segregation process during deposition and annealing, ${ }^{20}$ and by the intermolecular forces between polymer and fullerene derivatives. ${ }^{16}$ Recent studies have examined means to modify these interfacial interactions. In particular, the use of poly(ethylene glycol) (PEG) ${ }^{21}$ or PEG grafted PCBM,$^{22,23}$ have been explored as additives to control the nano- and microstructure of the active layer, and so to produce highly stable and efficient polymer solar cells. Jeng et al. recently established the role of poly(ethylene glycol) dimethyl ether as an electrode buffer for the fabrication of high performance (poly-3-hexylthiophene, P3HT):PCBM based organic photovoltaics (OPVs). ${ }^{22}$ PEG-C $_{60}$ adducts have been variously proposed as nucleants for the fullerene rich electron transporting phase, ${ }^{23}$ as a means to assemble an active dipole at the electrode interface, ${ }^{21}$ and as an encapsulant against oxidation. ${ }^{23}$ However, the uses of short chain, multi-fullerene end-capped linear or branched PEGs, or mixtures thereof, have not yet been explored in this context. Such multiply-bound fullerenes may offer additional opportunities to enhance device performance, potentially acting as more effective nucleants, inherently bringing together groups of fullerenes. At the 
same time, reducing the proportion of hygroscopic PEG should decrease the sensitivity of the device to moisture.

Synthetically, the preparation of multi-fullerene end-capped PEG dumbbells and stars has already been addressed via azide chemistry. ${ }^{24,25}$ However, these reactions with fullerenes do not yield pure mono-substituted adducts. ${ }^{26}$ The possible addition of more than one PEG-azide to a single fullerene creates a mixture of large molecules that is hard to separate. The onestep transesterification of PCBM provides a simple alternative that has not yet been exploited for the preparation of multifullerene end-capped PEGs. To date, the mono-fullerene endcapped PEG chains used in BHJ studies have had polymer weights of 2000-4000 Da. The large number of hygroscopic ethylene oxide repeat units per fullerene ( $c a$. one $\mathrm{C}_{60}$ per 45-90 monomers) makes the devices highly moisture sensitive. ${ }^{21-23}$ Finally, in order to improve control during the BHJ phase segregation, it would be desirable to use pure, monodisperse PEG-PCBM materials as it is anticipated that these will enhance the self-assembly of ordered, well-defined structures. ${ }^{27}$ The present study develops a synthetic protocol for the preparation of multi-fullerene, end-capped polydisperse linear PEGs, and three- and four-arm PEG stars. Several challenges were encountered during isolation of fully fullerene end-capped PEGs. These difficulties were addressed by the preparation of a monodisperse multi-fullerene end-capped three-arm PEG homostar. Traditionally, such PCBM derivatives have been synthesised by first hydrolysing the methyl ester into carboxylic acid to give [6,6]-phenyl- $\mathrm{C}_{61}$-butyric acid (PCBA), and then converting to the acid chloride for further condensation. ${ }^{28}$ However, the carboxylic acid derivative (PCBA) is only sparingly soluble in organic solvent (ortho-dichlorobenzene or carbon disulphide) which limits large scale synthesis. Instead, in this paper, the multi-fullerene stars were prepared via a single step catalytic transesterification with dibutyltinoxide (DBTO). ${ }^{29}$ This approach avoids the multistep synthetic route and more importantly, the low solubility of PCBA during the synthesis.

\section{Experimental}

\section{Materials and methods}

Poly(ethylene glycol) $\left[1, \quad \mathrm{PEG}_{\sim 4}(\mathrm{OH})_{2}\right.$, average molecular weight, $\left.M_{\mathrm{n}} \sim 200\right]$, glycerol ethoxylate $\left[2, \mathrm{PEG}_{\sim 21}(\mathrm{OH})_{3}\right.$, average $\left.M_{\mathrm{n}} \sim 1000\right]$, pentaerythritol ethoxylate $\left[3, \mathrm{PEG}_{\sim 15}(\mathrm{OH})_{4}\right.$ average $\left.M_{\mathrm{n}} \sim 797\right]$ were bought from Sigma-Aldrich and azeotropically dried by evaporation from anhydrous acetonitrile (99.8\%, Sigma-Aldrich) prior to use. 1,3,5-Tris(octagoloxymethyl)benzene $\left[7, \mathrm{PEG}_{24}(\mathrm{OH})_{3}\right]$ was synthesized according to the procedure recently reported and similarly azeotropically dried. ${ }^{30}$ Dibutyltinoxide (DBTO, 98\%, Sigma-Aldrich) was dried at $200{ }^{\circ} \mathrm{C}$ in vacuo for 30 min prior to use. Phenyl- $\mathrm{C}_{61}$-butyric acid methyl ester (PCBM, >99\%, Solenne BV) was dried under vacuum at room temperature prior to use. Silica gel for column chromatography [Geduran ${ }^{\circledR}$ Si $60(40-63 \mu \mathrm{m})$, Merck] was neutralised using sodium bicarbonate (VWR). Trans-2-[3-(4-tertbutylphenyl)-2-methyl-2-propenylidene]malononitrile

(DCTB)
(>98\%, Sigma-Aldrich ) and sodium iodide (99.999\%, SigmaAldrich) were used as the matrix for MALDI-TOF mass spectrometry. ortho-Dichlorobenzene (o-DCB) (anhydrous, $>99.8 \%$, Sigma-Aldrich), trifluoroacetic anhydride (TFAA) ( $\geq 99.8 \%$, Sigma-Aldrich), thin layer chromatography plates (TLC Silica gel $60 \mathrm{~F}_{254}$, Merck), toluene, tetrahydrofuran and methanol (HPLC grade, VWR) were purchased and used as received.

\section{Characterization}

Mass spectrometry. Matrix-assisted laser desorption ionization time-of-flight (MALDI-TOF) mass spectral data were acquired on a Waters MICROMASS ${ }^{\circledR}$ MALDI micro $\mathrm{MX}^{\mathrm{TM}}$ with a nitrogen laser at $333 \mathrm{~nm}$ (power range from 150-220 mW), in the positive reflectron mode with delayed extraction. Analytical samples $(1-2 \mathrm{mg})$ dissolved in toluene $(10 \mu \mathrm{L})$ were added to a mixture of DCTB matrix in THF $\left(10 \mathrm{mg} \mathrm{mL}^{-1}, 10 \mu \mathrm{L}\right)$ and NaI in THF $\left(3 \mathrm{mg} \mathrm{mL}{ }^{-1}, 3 \mu \mathrm{L}\right)$. A small aliquot of this mixture $(3 \mu \mathrm{L})$ was loaded onto a cold stainless steel target plate and allowed to air dry at room temperature. The instrument was calibrated in the range of 500-5000 Da using a poly(ethylene glycol) standard. The simulated isotopic peak patterns were constructed using online software MolE - Molecular Mass Calculator v2.02 (http://rna-mdb.cas.albany.edu/RNAmods/ masspec/mole.htm).

\section{NMR spectroscopy}

NMR spectra were acquired using a Bruker AM 400 spectrometer operating at $9.4 \mathrm{~T}$. Samples were dissolved in $\mathrm{CDCl}_{3}$ and all spectra were recorded with 16 scans and $D_{1}=1 \mathrm{~s}$. All chemical shifts $(\delta)$ are given in $\mathrm{ppm}$, where the residual $\mathrm{CHCl}_{3}$ peak was used as an internal reference for ${ }^{1} \mathrm{H}$ NMR $\left(\delta_{\mathrm{H}}=7.28 \mathrm{ppm}\right)$, and the $\mathrm{CDCl}_{3}$ peak for ${ }^{13} \mathrm{C}$ NMR $\left(\delta_{\mathrm{C}}=78.23 \mathrm{ppm}\right)$. Coupling constants $(J)$ are given in $\mathrm{Hz}$, and chemical splitting patterns are abbreviated as follows: s, singlet; $\mathrm{d}$, doublet; $\mathrm{t}$, triplet; $\mathrm{q}$, quartet; quin, quintet and $\mathrm{m}$, multiplet.

\section{UV-vis spectroscopy}

UV-visible spectra were collected using a Perkin-Elmer Lambda 950 spectrophotometer. Samples were dissolved in toluene and spectra were recorded from 200 to $800 \mathrm{~nm}$ with a resolution of $1 \mathrm{~nm}$, using a $1.0 \mathrm{~cm}$ UV quartz cuvette.

\section{FTIR spectroscopy}

Fourier transform infrared spectra were recorded on powders using a Perkin-Elmer spectrometer 100 equipped with a Pike attenuated total reflectance (ATR) silicon crystal.

\section{General procedure for synthesis of fullerene end-capped PEGs}

PCBM [1.1 eq. for each $\operatorname{PEG}(\mathrm{OH})_{n}$ hydroxyl group] was dissolved in $o$-DCB $(10 \mathrm{~mL})$ under $\mathrm{N}_{2}$ at room temperature, and added to PEG and DBTO [0.11 eq. for each PEG $(\mathrm{OH})_{\mathrm{n}}$ hydroxyl group] in a two-necked round-bottomed flask. The solution was then heated at $140{ }^{\circ} \mathrm{C}$ for 5 days under $\mathrm{N}_{2}$, after which the solvent was evaporated under a stream of $\mathrm{N}_{2}$ at room temperature, and the resulting dark brown residue fractionated by silica gel column chromatography. Unreacted PCBM eluted 
with toluene, after which fractions were collected by eluting with toluene-methanol $(9: 1 \mathrm{v} / \mathrm{v})$. Depending on their purity, as determined by ${ }^{1} \mathrm{H} \mathrm{NMR}$, the fractions were further purified, either by additional column chromatography and/or preparative TLC until the ${ }^{1} \mathrm{H}$ NMR integral of the peaks remained constant upon further purification.

\section{Synthesis of PEG $_{\sim 4}(\mathrm{OPCB})_{2}, 4$}

Polydisperse bis- $_{60}$ linear PEG 4 was synthesized from $\mathrm{PEG}_{\sim 4}(\mathrm{OH})_{2} \quad(\mathbf{1}, 30 \mathrm{mg}, 0.14 \mathrm{mmol})$, PCBM $(280 \mathrm{mg}$, $0.31 \mathrm{mmol})$ and DBTO (8 $\mathrm{mg}, 0.03 \mathrm{mmol})$ using the general method described above, and fractionated through a single silica gel column, eluting with toluene-methanol $(9 / 1 \mathrm{v} / \mathrm{v})$, to give $\mathrm{PEG}_{\sim 4}(\mathrm{OPCB})_{2}(4,25 \mathrm{mg}, 9 \%)$ as a brown solid. $R_{\mathrm{f}}$ toluene-methanol $(9: 1 \mathrm{v} / \mathrm{v}) 0.43 ; \delta_{\mathrm{H}}\left(400 \mathrm{MHz}, \mathrm{CDCl}_{3}\right) 2.20$ (quin, $J=7.6 \mathrm{~Hz}, 4 \mathrm{H}), 2.57(\mathrm{t}, J=7.3 \mathrm{~Hz}, 4 \mathrm{H}), 2.93(\mathrm{t}, J=$ $8.1 \mathrm{~Hz}, 4 \mathrm{H}), 3.60-3.77(\mathrm{~m}, 17 \mathrm{H}), 4.25(\mathrm{t}, J=4.3 \mathrm{~Hz}, 4 \mathrm{H}), 7.49$ $(\mathrm{t}, J=7.5 \mathrm{~Hz}, 2 \mathrm{H}), 7.56(\mathrm{t}, J=7.6 \mathrm{~Hz}, 4 \mathrm{H}), 7.93(\mathrm{~d}, J=7.9 \mathrm{~Hz}$, 4H) ppm; $\nu$ (FT-IR; ATR) 2917 (aliphatic $\boldsymbol{C}-\boldsymbol{H}$ stretching), 2855 (aliphatic $\boldsymbol{C}-\boldsymbol{H}$ stretching), 1732 (carbonyl stretching of PCBM ester), 1599, 1562, 1493, 1374, 1021 ( $\boldsymbol{C}-\boldsymbol{O}$ symmetric stretching of PEG), 797, 755, $695 \mathrm{~cm}^{-1}$; $\lambda$ (UV-vis; toluene) 330, 433, $510 \mathrm{~nm} ; \mathrm{m} / z$ (MALDI-TOF) calc'd for $\left[\mathrm{C}_{152} \mathrm{H}_{42} \mathrm{O}_{8} \mathrm{Na}\right]^{+} 2017.23$ $\mathrm{m} / z$, found $[\mathrm{M}+\mathrm{Na}]^{+} 2017.21 \mathrm{~m} / \mathrm{z}$.

\section{Synthesis of mixture of $\mathrm{PEG}_{\sim 21}(\mathrm{OPCB})_{3}, 5 \mathrm{a}$, and} PEG $_{\sim 21}(\mathrm{OPCB})_{2}(\mathrm{OH}), 5 \mathrm{~b}$

Polydisperse tris- $\mathrm{C}_{60}$ 3-arm branched PEG 5a was synthesized from $\mathrm{PEG}_{\sim 21}(\mathrm{OH})_{3}(2,50 \mathrm{mg}, 0.05 \mathrm{mmol})$, PCBM (150 mg, $0.16 \mathrm{mmol}$ ) and DBTO (4 mg, $0.01 \mathrm{mmol})$ using the general method described above, and fractionated through silica gel columns $(2 \times)$, followed by preparative TLC $(3 \times)$, eluting with toluene-methanol $(9: 1 \mathrm{v} / \mathrm{v})$, to give a mixture of $\mathrm{PEG}_{\sim 21}(\mathrm{OPCB})_{3} \quad$ (5a) and $\mathrm{PEG}_{\sim 21}(\mathrm{OPCB})_{2}(\mathrm{OH})$ (5b) $(40 \mathrm{mg}$, 22\%, 5a: 5b ca. $1: 9$ by ${ }^{1} \mathrm{H}$ NMR integration) as a brown solid. $R_{\mathrm{f}}$ toluene-methanol $(9: 1 \mathrm{v} / \mathrm{v}) 0.30 ; \delta_{\mathrm{H}}\left(400 \mathrm{MHz}, \mathrm{CDCl}_{3}\right) 2.08$ (s, 5H), 2.20 (quin, $J=7.8 \mathrm{~Hz}, 4.4 \mathrm{H}$ ), 2.57 (t, $J=7.5 \mathrm{~Hz}, 4.4 \mathrm{H}$ ), $2.91(\mathrm{t}, J=8.1 \mathrm{~Hz}, 4.4 \mathrm{H}), 3.47-3.85(\mathrm{~m}, 84.6 \mathrm{H}), 4.25(\mathrm{t}, J=$ $4.3 \mathrm{~Hz}, 4.4 \mathrm{H}), 7.49(\mathrm{t}, J=7.5 \mathrm{~Hz}, 2.2 \mathrm{H}), 7.57(\mathrm{t}, J=7.6 \mathrm{~Hz}$, $4.4 \mathrm{H}$ ), 7.94 (d, $J=7.9 \mathrm{~Hz}, 4.4 \mathrm{H}) \mathrm{ppm}$; $($ FT-IR; ATR) 2912 (aliphatic $\boldsymbol{C}-\boldsymbol{H}$ stretching), 2862 (aliphatic $\boldsymbol{C}-\boldsymbol{H}$ stretching), 1731 (carbonyl stretching of PCBM ester), 1600, 1446, 1428 ( $C=C$ stretching in fullerene), 1348, 1294, 1247, 1095 (C-O symmetric stretching of PEG), 944, 848, 755, $699 \mathrm{~cm}^{-1} ; \lambda$ (UV-vis; toluene) 330, 433, $510 \mathrm{~nm} ; \mathrm{m} / z$ (MALDI-TOF) calc'd for $\left[\mathrm{C}_{256} \mathrm{H}_{118} \mathrm{O}_{26} \mathrm{Na}\right]^{+} 3629.78 \mathrm{~m} / \mathrm{z}$, found $[\mathrm{M}+\mathrm{Na}]^{+} 3627.87 \mathrm{~m} / \mathrm{z}$.

Synthesis of mixture of $\mathrm{PEG}_{\sim 15}(\mathrm{OPCB})_{4}, 6 \mathrm{a}$, and PEG $_{\sim 15}(\mathrm{OPCB})_{3}(\mathrm{OH}), 6 \mathrm{~b}$

Polydisperse tetrakis- $\mathrm{C}_{60}$ 4-arm branched PEG 6 was synthesized from $\mathrm{PEG}_{\sim \mathbf{1 5}}(\mathrm{OH})_{4}(3,40 \mathrm{mg}, 0.05 \mathrm{mmol})$, PCBM (200 $\mathrm{mg}, 0.22 \mathrm{mmol}$ ) and DBTO (5 mg, $0.02 \mathrm{mmol}$ ) using the general method described above, and fractionated through silica gel columns $(2 \times)$, followed by preparative TLC $(3 \times)$, eluting with toluene-methanol $(9: 1 \mathrm{v} / \mathrm{v})$, to give a mixture of $\mathrm{PEG}_{\sim \mathbf{1 5}}(\mathrm{OPCB})_{4}(\mathbf{6 a})$ and $\mathrm{PEG}_{\sim \mathbf{1 5}}(\mathrm{OPCB})_{3}(\mathrm{OH})(\mathbf{6 b})(35 \mathrm{mg}$,
16\%, 6a : $6 \mathbf{b}$ ca. $1: 1$ by ${ }^{1} \mathrm{H}$ NMR integration) as a brown solid. $R_{\mathrm{f}}$ toluene-methanol $(9: 1 \mathrm{v} / \mathrm{v}) 0.32 ; \delta_{\mathrm{H}}\left(400 \mathrm{MHz}, \mathrm{CDCl}_{3}\right) 2.21$ (quin, $J=7.7 \mathrm{~Hz}, 8.1 \mathrm{H}), 2.58(\mathrm{t}, J=7.5 \mathrm{~Hz}, 8.1 \mathrm{H}), 2.94(\mathrm{t}, J=$ $8.1 \mathrm{~Hz}, 8.1 \mathrm{H}), 3.45(\mathrm{~s}, 5.4 \mathrm{H}), 3.53-3.67(\mathrm{~m}, 61.2 \mathrm{H}), 4.26(\mathrm{t}, J=$ $4.3 \mathrm{~Hz}, 7.5 \mathrm{H}), 7.50(\mathrm{t}, J=7.5 \mathrm{~Hz}, 4.1 \mathrm{H}), 7.58(\mathrm{t}, J=7.6 \mathrm{~Hz}$, 8.1H), 7.95 (d, $J=7.9 \mathrm{~Hz}, 8.1 \mathrm{H}) ; \nu$ (FT-IR; ATR) 2924 (aliphatic $\boldsymbol{C}-\boldsymbol{H}$ stretching), 2862 (aliphatic $\boldsymbol{C}-\boldsymbol{H}$ stretching), 1731 (carbonyl stretching of PCBM ester), 1602, 1423 ( $C=C$ stretching in fullerene), 1242, 1093 ( $\boldsymbol{C}-\boldsymbol{O}$ symmetric stretching of PEG), 952, 796, 755, $700 \mathrm{~cm}^{-1} ; \lambda$ (UV-vis; toluene) 330, 433, $510 \mathrm{~nm} ; \mathrm{m} / z$ (MALDI-TOF) calc'd for $\left[\mathrm{C}_{319} \mathrm{H}_{112} \mathrm{O}_{23} \mathrm{Na}\right]^{+} 4331.75 \mathrm{~m} / z$, found $[\mathrm{M}+\mathrm{Na}]^{+} 4332.85 \mathrm{~m} / \mathrm{z}$.

\section{Synthesis of $\mathrm{PEG}_{24}(\mathrm{OPCB})_{3}, 8$}

Monodisperse tris- $\mathrm{C}_{60} 3$-arm branched PEG 8 was synthesized from $\mathrm{PEG}_{24}(\mathrm{OH})_{3}(7,25 \mathrm{mg}, 0.02 \mathrm{mmol})$, PCBM (60 mg, $0.06 \mathrm{mmol})$ and DBTO (1.6 mg, $0.007 \mathrm{mmol})$ using the general method described above, and fractionated through silica gel columns $(2 \times)$, followed by preparative TLC $(3 \times)$, eluting with toluene-methanol $(9: 1 \mathrm{v} / \mathrm{v})$, to give $\mathrm{PEG}_{24}(\mathrm{OPCB})_{3}(\mathbf{8}, 4 \mathrm{mg}$, $5 \%)$ as a brown solid. $R_{\mathrm{f}}$ toluene-methanol $(9: 1 \mathrm{v} / \mathrm{v}) \quad 0.35$; $\delta_{\mathrm{H}}\left(400 \mathrm{MHz}, \mathrm{CDCl}_{3}\right) 2.21$ (quin, $\left.J=8.1 \mathrm{~Hz}, 6 \mathrm{H}\right), 2.57(\mathrm{t}, J=$ $7.5 \mathrm{~Hz}, 6 \mathrm{H}), 2.93(\mathrm{t}, J=8.1 \mathrm{~Hz}, 6 \mathrm{H}), 3.61-3.76(\mathrm{~m}, 96 \mathrm{H}), 4.25(\mathrm{t}$, $J=4.3 \mathrm{~Hz}, 6 \mathrm{H}), 4.56(\mathrm{~s}, 6 \mathrm{H}), 7.25(\mathrm{~s}, 3 \mathrm{H}), 7.51(\mathrm{t}, J=7.5 \mathrm{~Hz}$, $3 \mathrm{H}), 7.57$ (t, $J=7.6 \mathrm{~Hz}, 6 \mathrm{H}), 7.94$ (d, $J=7.9 \mathrm{~Hz}, 6 \mathrm{H}) ; \nu$ (FT-IR; ATR) 2922 (aliphatic $\boldsymbol{C}-\boldsymbol{H}$ stretching), 2852 (aliphatic $\boldsymbol{C}-\boldsymbol{H}$ stretching), 1728 (carbonyl stretching of PCBM ester), 1462, 1378, 1265 ( $\boldsymbol{C}-\boldsymbol{C}$ stretching in fullerene), 1079 ( $\boldsymbol{C}-\boldsymbol{O}$ symmetric stretching of PEG), 1045, 889, $722 \mathrm{~cm}^{-1} ; \mathrm{m} / z$ (MALDI-TOF) calc'd for $\left[\mathrm{C}_{270} \mathrm{H}_{138} \mathrm{O}_{30} \mathrm{Na}\right]^{+} 3881.92 \mathrm{~m} / z$, found $[\mathrm{M}+\mathrm{Na}]^{+}$ $3881.83 \mathrm{~m} / \mathrm{z}$.

\section{Results and discussion}

Multifullerene-end-capped PEGs, $\mathrm{PEG}_{\sim 4}(\mathrm{OPCB})_{2} \quad$ (4), $\mathrm{PEG}_{\sim 21}(\mathrm{OPCB})_{3}(\mathbf{5 a}), \mathrm{PEG}_{\sim 15}(\mathrm{OPCB})_{4}(\mathbf{6 a})$ and $\mathrm{PEG}_{24}(\mathrm{OPCB})_{3}$ (8) were synthesized via a one-step transesterification of PCBM with the corresponding hydroxyl-terminated PEG derivatives [polydisperse $\mathrm{PEG}(\mathrm{OH})_{\mathrm{n}} \mathbf{1 - 3}$, and monodisperse $\mathrm{PEG}_{24}(\mathrm{OH})_{3}$ 7] in the presence of a catalytic amount of dibutyltinoxide (DBTO), at $140{ }^{\circ} \mathrm{C}$ in dry ortho-dichlorobenzene (o-DCB) (Scheme 1). ${ }^{29}$ Small aliquots from the crude reaction mixture were analysed after $2 \mathrm{~h}$, and then every $24 \mathrm{~h}$, up to 5 days by ${ }^{1} \mathrm{H}$ NMR. ${ }^{1} \mathrm{H}$ NMR analysis (see ESI, $\dagger$ Fig. S1) showed the appearance and growth of a new triplet signal at $4.25 \mathrm{ppm}$ corresponding to the newly formed methylene ester protons $\left(-\mathrm{CH}_{2}-\mathrm{O}-\mathrm{C}=\mathrm{O}\right){ }^{21}$ The signal intensity increased significantly during the first three days, after which point growth slowed, indicating that the transesterification reaction could proceed no further. As no pure mono-disperse $\mathrm{PEG}_{n}(\mathrm{OH})_{3 / 4}$ (2 or 3) were commercially available, the study commenced with polydisperse $\quad \mathrm{PEG}_{\sim 4}(\mathrm{OH})_{2} \quad(\mathbf{1}$, average molecular weight $M_{\mathrm{n}} \sim 200$ manufacturer value; $M_{\mathrm{n}}=203$ from NMR, see below), PEG $_{\sim 21}(\mathrm{OH})_{3}\left(2\right.$, average $M_{\mathrm{n}} \sim 1000$ manufacturer value; $M_{\mathrm{n}}=$ 1029 from NMR) and $\mathrm{PEG}_{\sim 15}(\mathrm{OH})_{4}\left(3\right.$, average $M_{\mathrm{n}} \sim 797$ manu- 


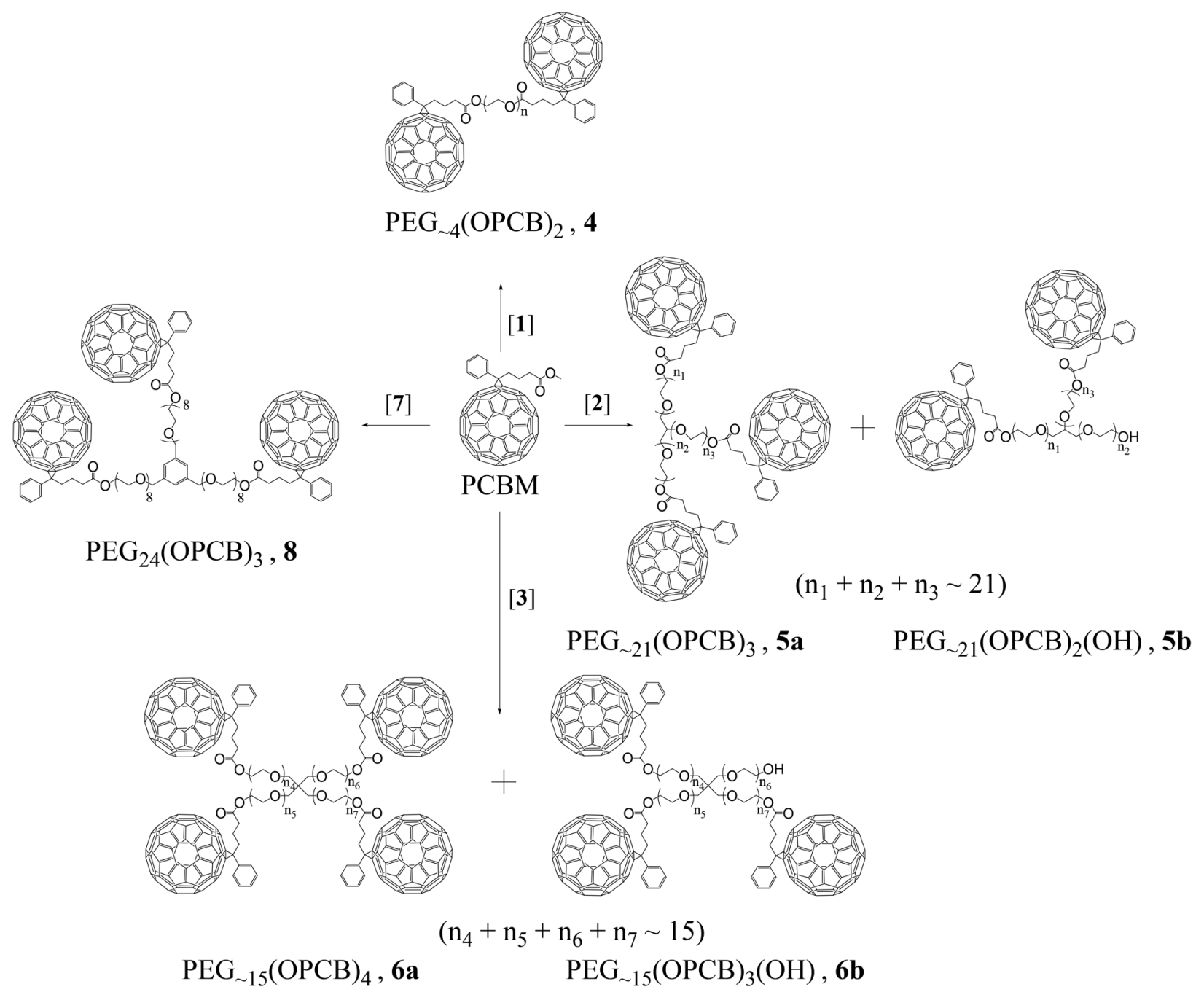

Reaction condition : 1.1 eq PCBM per $\mathrm{OH}, 0.11$ eq DBTO per $\mathrm{OH}, o$-DCB, $140^{\circ} \mathrm{C}, \mathrm{N}_{2}, 5$ days

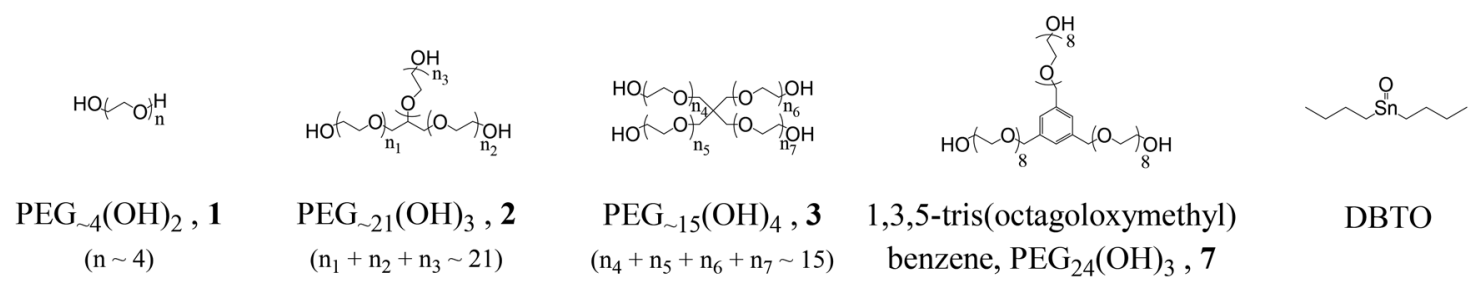

Scheme 1 The transesterification of $\mathrm{PCBM}$ with $\mathrm{PEG}_{x}(\mathrm{OH})_{n}(1-3)$ and $\mathrm{PEG}_{24}(\mathrm{OH})_{3}(7)$ to yield polydisperse $\mathrm{PEG} \mathrm{G}_{x}(\mathrm{OPCB})_{n}(4-6)$ and monodisperse $\mathrm{PEG}_{24}(\mathrm{OPCB})_{3}(8)$.

facturer value; $M_{\mathrm{n}}=786$ from NMR). After azeotropic drying with acetonitrile, these cores were used for the preparation of $\mathrm{PEG}_{\sim 4}(\mathrm{OPCB})_{2}(\mathbf{4}), \mathrm{PEG}_{\sim 21}(\mathrm{OPCB})_{3}(\mathbf{5 a})$, and $\mathrm{PEG}_{\sim 15}(\mathrm{OPCB})_{4}$ (6a), respectively, and the resulting compounds were purified by column and/or preparative thin layer chromatography (TLC). MALDI-TOF mass spectral analysis, supported by ${ }^{1} \mathrm{H}$ NMR, FTIR and UV-vis techniques, were used for characterization of the phenyl- $\mathrm{C}_{61}$-butyryl (PCB)-functionalised PEGs.

The extent of the transesterification reaction can be determined by the ratio of the chain terminal proton resonances to the polymeric backbone. However, the resonances at around $3.7 \mathrm{ppm}$ corresponding to methylene (alpha proton, $\alpha$ ) bearing the terminal hydroxyl groups overlap with the PEG backbone. To establish a suitable control and confirm the nature of starting materials, each starting $\mathrm{PEG}_{x}(\mathrm{OH})_{n}$ was treated with highly reactive trifluoroacetic anhydride (TFAA) $-\mathrm{CDCl}_{3}(1: 19 \mathrm{v} / \mathrm{v})$ in an NMR tube to give the corresponding per-acylated $\mathrm{PEG}_{x^{-}}$ $\left(\mathrm{OCOCF}_{3}\right)_{n}$ derivative in situ. ${ }^{31}$ The electronegative trifluoroacetyl substituent deshields the adjacent acyloxymethylene protons (alpha proton, $\alpha$ ), $\mathrm{F}_{3} \mathrm{CCO}_{2} \mathrm{CH}_{2} \mathrm{CH}_{2} \mathrm{O}$, giving a signal at 
ca. $4.51 \mathrm{ppm}$ well resolved from the PEG backbone. Thus, the average number of repeating units of each PEG compound was obtained from the integral ratio of the acyloxymethylene protons to the main PEG signals (see ESI, $\uparrow$ Fig. S3-5), and found to be 4, 21 \& 15 for bis-OH, tris-OH and tetrakis-OH terminated PEGs respectively. These ${ }^{1} \mathrm{H}$ NMR findings are consistent with the number average of molecular weight distributions in the MALDI spectra of the pure PEG cores
(ESI, $\dagger$ Fig. S8-9). The ${ }^{1} \mathrm{H}$ NMR of $\mathrm{PEG}_{\sim 15}\left(\mathrm{OCOCF}_{3}\right)_{4}(\mathrm{ESI}, \dagger$ Fig. S5) indicated that the tetrakis-OH terminated PEG contains a distinctive second variant; most likely a fraction of the mixture has a $\mathrm{CH}_{2}-\mathrm{OH}$ stub directly linked to the central $\mathrm{sp}^{3}$ carbon, rather than through an ether linkage, i.e. in 3, one of $n_{4 / 5 / 6 / 7}=0$; (see $\mathrm{ESI} \uparrow$ for detailed characterisation). Since PCBM is a bulky molecule, a relatively longer side chain should assist the grafting reaction; steric effects may prevent
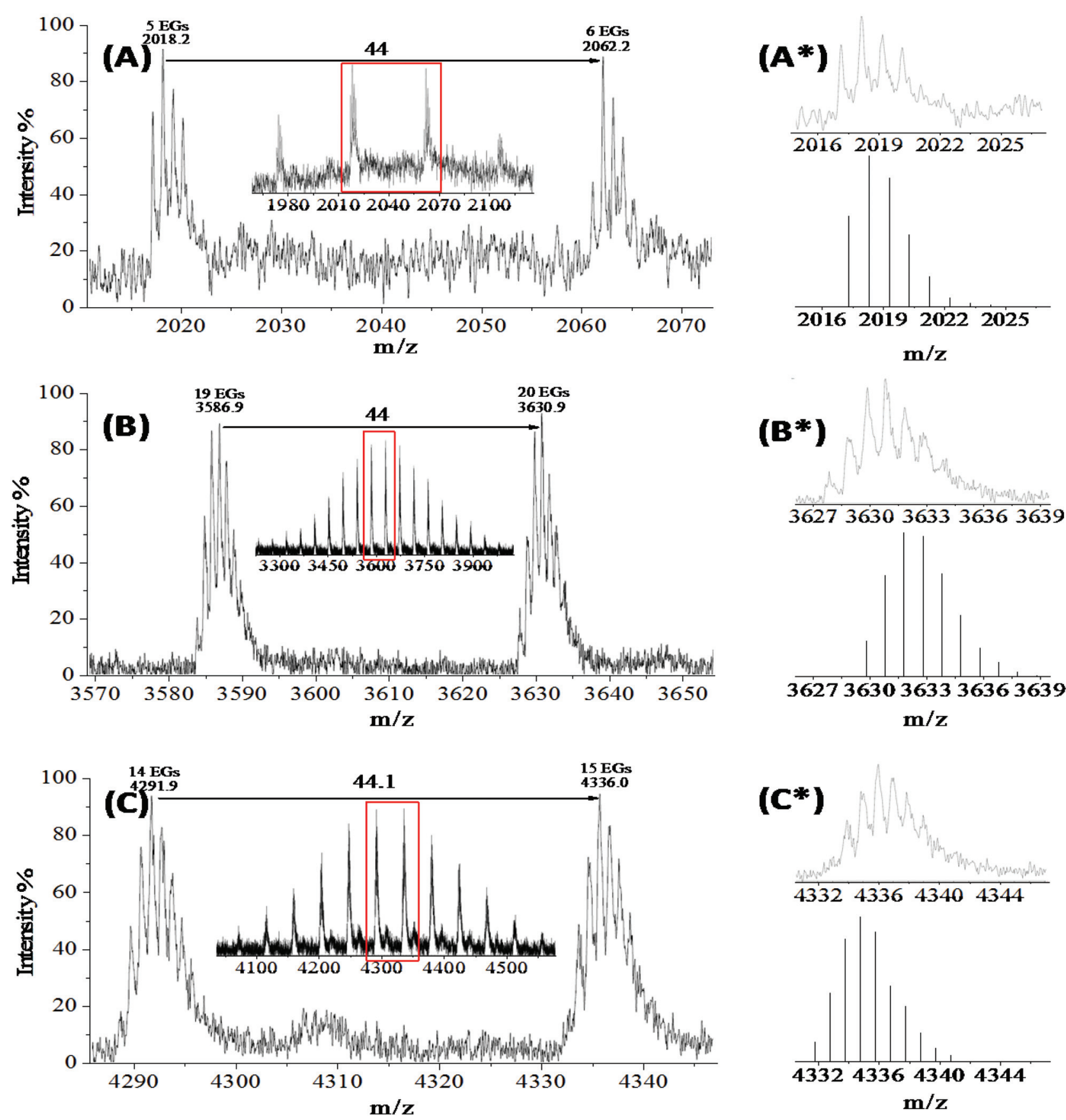

Fig. 1 Experimental and simulated MALDI-TOF mass spectra of $\left[P E G(O P C B)_{n}+N^{2}\right]^{+}(4-6)$ confirming successful transesterification of PCBM with polydisperse PEGs 1-3: (A) PEG $\sim 4$ (OPCB) $)_{2}$ (4); (B) $\mathrm{PEG}_{\sim 21}(\mathrm{OPCB})_{3}$ (5); (C) $\mathrm{PEG}_{\sim 15}(\mathrm{OPCB})_{4}$ (6). The full spectra are given in the ESI. $\dagger$ For each of 4-6, the whole product cluster (inset) is expanded in the region of the red rectangle to show the PEG monomer spacing, and further expanded ( $A^{*}, n=5$; $\mathrm{B}^{\star} n=20$; and $\mathrm{C}^{*}, n=15$ ) to show the monoisotopic peak pattern (top), with comparison to the corresponding simulated peak pattern (below). 
fullerene attaching onto short side chains, particularly onto the $\mathrm{CH}_{2} \mathrm{OH}$ stub.

The MALDI-TOF mass spectrum of $\mathrm{PEG}_{\sim 4}(\mathrm{OPCB})_{2}$ (4) (Fig. 1A) verified the formation of doubly transesterified PEG $_{\sim 4}(\mathrm{OH})_{2}$, showing four main clusters of positively charged $[\mathrm{M}+\mathrm{Na}]^{+}$ions ranging from $\mathrm{m} / \mathrm{z} 1970$ to 2160, where each peak region corresponds to the bis-fullerene end-capped PEG dumbbells with between 4 and 7 ethylene oxide repeat units (see ESI, $\uparrow$ Fig. S10 for the full MALDI-TOF mass spectrum of 4; no mono-fullerene substituted species is visible). Considering the penta-ethylene oxide repeat unit cluster in detail (Fig. 1A*, upper), the experimental isotopic peak pattern of $\mathrm{PEG}_{\sim 4}(\mathrm{OPCB})_{2}$ (4) was consistent with the simulated pattern (Fig. 1A* $\mathrm{A}^{*}$ lower) across all expected masses, $[\mathrm{M}+\mathrm{Na}]^{+}{ }_{\text {obs }}=$ 2017.23, $[\mathrm{M}+\mathrm{Na}]_{\text {calc }}^{+}=2017.21$. In the IR spectrum of 4 (Fig. 2b), there is no $\mathrm{OH}$ stretch at around $3500 \mathrm{~cm}^{-1}$, indicating that there is very little, if any mono-fullerene substituted $\mathrm{PEG}_{\sim 4}$ in the product fraction. In the ${ }^{1} \mathrm{H}$ NMR spectrum of $\mathrm{PEG}_{\sim 4}(\mathrm{OPCB})_{2}$ (ESI, $\dagger$ Fig. S11), a new triplet at 4.25 ppm indicates the successful acylation of the linear PEG. The observed integral ratio between the newly formed acyloxymethylene resonance (alpha protons) and the main PEG signal was
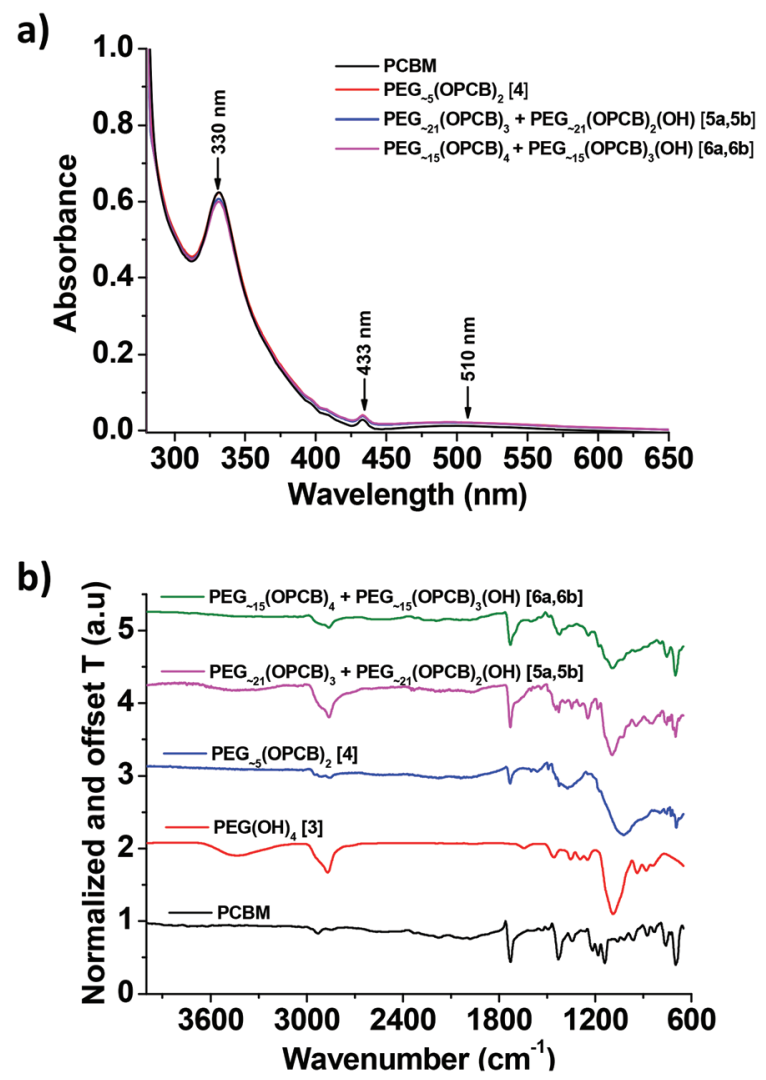

Fig. 2 Photospectrometric data for PCB-capped PEG dendrimers: (a) UV-vis spectra of PCBM, PEG ${ }_{\sim 4}(\mathrm{OPCB})_{2}$ (4), $\mathrm{PEG}_{\sim 21}(\mathrm{OPCB})_{3}$ \& $\mathrm{PEG}_{\sim 21}(\mathrm{OPCB})_{2}(\mathrm{OH})\left(5 \mathrm{a}\right.$ and $5 \mathrm{~b}$ ), and $\mathrm{PEG}_{\sim 15}(\mathrm{OPCB})_{4}$ \& $\mathrm{PEG}_{\sim 15}(\mathrm{OPCB})_{3^{-}}$ $(\mathrm{OH})(6 \mathrm{a}$ and $6 \mathrm{~b})$ recorded in toluene. Each concentration was adjusted to around $\mathrm{Abs}_{330 \mathrm{~nm}} \sim 0.6$ for ease of comparison; (b) FTIR spectra of PCBM, PEG ${ }_{\sim 15}(\mathrm{OH})_{4}$ (3), $\mathrm{PEG}_{\sim 4}(\mathrm{OPCB})_{2}$ (4), $\mathrm{PEG}_{\sim 21}(\mathrm{OPCB})_{3}$ (5) and $\mathrm{PEG}_{\sim 15}(\mathrm{OPCB})_{4}(6)$.
$1: 4.25$, whereas the ratio observed in fully trifluoroacetylated linear PEG was $1: 3.25$, Rather than incomplete reaction, the IR evidence suggests that this shift in ratio is more likely to arise due to the preferential double reaction of the longer PEG chains, because of steric constraints on the second fullerene addition. From the observed integral ratio, the as produced dumbbell derived under these conditions contains an average of 5 repeating units whereas the starting $\mathrm{PEG}_{\sim 4}(\mathrm{OH})_{2}$ has an average of 4 repeating units.

The purifications of all bis-, tris- and tetrakis-fullerene adducts were performed by multiple rounds of column chromatography and preparative TLC. Since PEGs bearing unreacted hydroxyl groups have a stronger affinity for silica gel, any remaining partially unreacted PEG is eluted in the later fractions. The polarity of the molecules decreases with increasing number of covalently grafted non-polar fullerenes. Hence, the most highly substituted adducts are collected in the first fraction to elute using Toluene-MeOH 9:1 v/v. All detailed analyses were carried out with these initially eluted chromatographic fractions.

\section{Tris-fullerene substituted PEG}

The MALDI spectrum of 5 (ESI, $\uparrow$ Fig. S13) clearly confirms the successful formation of the tris-fullerene polymer (mean peak distribution at $\sim 3630 \mathrm{~m} / \mathrm{z}$ ). The observed monoisotopic mass of tris-fullerene substituted 3-arm PEG (with 20 repeating units) (Fig. 1B*) appeared to be shifted by $2 \mathrm{~m} / \mathrm{z}$ to lower mass, most likely due to the limit of spectrometer sensitivity. The overall shape of the monoisotopic mass reassembled that of the calculated value for the tris-fullerene substituted 3-arm PEG. However, two other peak distributions (mean peak distribution at around 2750 and $1740 \mathrm{~m} / z$ ) were also observed. Since the transesterification of fullerene and PEG hydroxyls is a sequential reaction, mono- and bis-fullerene substituted PEGs may be present along with the desired tris-fullerene adduct. In order to identify the origin of the peaks in the MALDI-TOF spectrum, each peak distribution corresponding to tris- and possible mono- and bis- fullerene PEG distributions were compared with that of the starting PEG (Fig. S14). $\dagger$ Both trisand bis-substituted species had an average of 20 repeating units (mean peak distribution at around 3630 and $2750 \mathrm{~m} / \mathrm{z}$ respectively), but the mono-substituted PEG peak had a mean peak distribution at around $1740 \mathrm{~m} / \mathrm{z}$, corresponding to an average of 17 repeating units. The expected mono-substituted 3-arm PEG would have an average of 20 repeating units with a mean peak distribution at around $1880 \mathrm{~m} / \mathrm{z}$; the difference of 3 repeating units between the observed mono-substituted species and the bis/tris substituted PEG star suggests that the mono-substituted distribution at $1740 \mathrm{~m} / \mathrm{z}$ may result from fragmentation of the bis/tris PEG stars. An alternative explanation is that the shorter mono-fullerene substituted 3-arm PEG is less polar and eluted preferentially with the more substituted products; however, the change in length would be expected to be less significant than the change in the number of available hydroxyls.

The high polydispersity of the fullerene end-capped PEG adducts $\mathrm{PEG}_{\sim 21}(\mathrm{OPCB})_{3}$ (5a) made chromatographic purification 
of very difficult; the variations in PEG molecular weight and degree of fullerene substitution smeared the variation in polarity. Hence, further efforts were made to isolate PEG $_{\sim 21}(\mathrm{OPCB})_{3}$ (5a) from its mixture by repeated column chromatography, and multiple preparative TLC (up to 3 times). However, the purity did not improve significantly despite these lengthy steps. The signal intensity ratio of the bis- and trisfullerene distribution in MALDI improved only to about $84: 16$ from 90:10 after initial work-up. As the MALDI signal intensity may not always reflect molecular abundance, the ratio was also determined from the ${ }^{1} \mathrm{H}$ NMR integral (Fig. S12 $\dagger$ ). In the case of $\mathrm{PEG}_{\sim 21}\left(\mathrm{OCOCF}_{3}\right)_{3}$, the ratio of chain terminal to backbone signals was 6:84 (confirming 21 ethylene oxide units per dendrimer molecule, as noted above). For the fullerene endcapped 3-arm dendrimer 5, the butyryl peaks of the PCB moiety and the acyloxymethylene of the chain termini are also well resolved from the polymeric PEG peak, and the corresponding ratio of fullerene ends to backbone signals was $4.3: 84$. Assuming that the product is a mixture of only $\mathrm{PEG}_{\sim 21}(\mathrm{OPCB})_{2}(\mathrm{OH})(\mathbf{5 b})$ and $\mathrm{PEG}_{\sim 21}(\mathrm{OPCB})_{3}(5 \mathbf{a})$, (i.e. that the mono-fullerene substituted PEG star signal in MALDI-TOF spectrum is due to fragmentation) the best fit for the $\alpha$-proton integration indicates a $90: 10$ ratio of $\mathrm{PEG}_{\sim 21}(\mathrm{OPCB})_{2}(\mathrm{OH})(\mathbf{5 b})$ to $\mathrm{PEG}_{\sim 21}(\mathrm{OPCB})_{3}(\mathbf{5 a})$, a value comparable to the ratio derived from the MALDI peak intensities $(84: 16)$.

\section{Tetrakis-fullerene substituted PEG}

The MALDI-TOF spectra of PEG $_{\sim 15}(\mathrm{OPCB})_{4} \quad$ (6a) and $\mathrm{PEG}_{\sim 15}(\mathrm{OPCB})_{3}(\mathrm{OH})(\mathbf{6 b})$ exhibited similar distribution patterns to the tris-fullerene substituted PEG, but with different masses, having mean peak distributions around 4330 and $3410 \mathrm{~m} / \mathrm{z}$ respectively (see ESI, $\dagger$ Fig. S16). The observed monoisotopic mass of the tetrakis-fullerene substituted 4-arm PEG (Fig. 1C ${ }^{*}$ ) appeared to be shifted by $2 \mathrm{~m} / \mathrm{z}$ but resembled the shape of the calculated monoisotopic mass (with 15 repeating units). Within the limits of the spectrometer sensitivity, the result confirmed the formation the desired $\mathrm{PEG}_{\sim 15}(\mathrm{OPCB})_{4}$ (6a). Similar to the synthesis of $\mathrm{PEG}_{\sim 21}(\mathrm{OPCB})_{3}(\mathbf{5 a})$, the incompletely substituted 4-arm PEG, $\mathrm{PEG}_{\sim 15}(\mathrm{OPCB})_{3}(\mathrm{OH})(\mathbf{6 b})$ was also observed in the spectrum at around $3410 \mathrm{~m} / \mathrm{z}$. An additional mass distribution corresponding to the possible bis-fullerene substituted adduct was also observed at around $2240 \mathrm{~m} / z$. However, detailed comparison (see ESI, $\uparrow$ Fig. S17) indicates that only the tris- and tetrakis-fullerene derivatives are likely to be primary signals. The tris- and tetrakis-fullerene distribution both have an average of 15 repeating units, whereas the bis-fullerene distribution was found to have an average of 8 repeating units. MALDI-TOF spectra of the starting 4-arm PEG (Fig. S9†) showed no evidence of any 8 repeating unit fraction within the polymer. Therefore, it is clear that the peak distribution at around $2240 \mathrm{~m} / \mathrm{z}$ in the tetrakis-fullerene substituted PEG spectra resulted from fragmentation of the higher mass species. Whilst the MALDI-TOF indicated a $50: 50$ ratio between the tris- and tetrakis-fullerene signal intensities (Fig. S16 $\dagger$ ), the NMR integral ratios provided a more reliable measure. The integral ratio of $\alpha$-protons versus the main PEG backbone protons for fully acylated $\mathrm{PEG}_{\sim 15}\left(\mathrm{OCOCF}_{3}\right)_{4}$ was 8:60 (see Fig. S5 $\uparrow$ ). The observed ratio of the corresponding tris- and tetrakis-fullerene substituted PEG star in the ${ }^{1} \mathrm{H}$ NMR of mixture of $(\mathbf{6 a}, \mathbf{6 b})$ was 7.4:60 (see Fig. S15 $\dagger$ ). Assuming that, as shown in the MALDI-TOF analysis, the NMR integration solely results from the contribution of tris- and tetrakis-substituted PEG $_{\sim 15}$ stars, the best fit to the $\alpha$-proton integration is a $1: 1$ ratio of $\mathrm{PEG}_{\sim 15}(\mathrm{OPCB})_{3}(\mathrm{OH})(\mathbf{6 b})$ to $\mathrm{PEG}_{\sim 15}(\mathrm{OPCB})_{4}$ (6a). As in the case of $\mathrm{PEG}_{\sim 21}(\mathrm{OPCB})_{3}$ (5a), extensive purification could not separate the species with differing degrees of fullerene substitution, presumably due to the level of PEG polydispersity.

Higher molecular mass species tend to be harder to ionise in MS and therefore peak intensity is not generally used in determination of natural abundance. ${ }^{32}$ However, considering the calculation based on the NMR peak integral, the values derived from both MALDI and NMR are very comparable. Although NMR integration is more reliable for determination of actual abundance, it seems that MALDI peak intensity could also be used as a good approximation in the current system.

The UV-vis spectra of $\mathrm{PEG}_{\sim 4}(\mathrm{OPCB})_{2}(4), \mathrm{PEG}_{\sim 21}(\mathrm{OPCB})_{3}(5)$ and $\mathrm{PEG}_{\sim 15}(\mathrm{OPCB})_{4}(6)$ products in toluene have three electronic absorption bands at 330, 433 and $510 \mathrm{~nm}$ (Fig. 2a), similar to PCBM, as expected. The retention of the optoelectronic properties should be helpful for PV applications. The starting PEG $(\mathrm{OH})_{n}$ (1-3) do not contribute to the absorbance (see ESI† Fig. S18 for UV-vis spectra of 1-3). ${ }^{23}$ However, in FTIR (Fig. 2b), the intensity of the $-\mathrm{OH}$ stretching bands at around $3400 \mathrm{~cm}^{-1}$ were significantly reduced in all products indicating successful transesterification. The $-\mathrm{OH}$ bands did not disappear completely in 3-arm 5 and 4-arm 6 as the substituted PEG still contained a small proportion of free terminal hydroxyl groups. As in previous reports, ${ }^{21,23}$ no spectral change was observed for the bands at $1732 \mathrm{~cm}^{-1}$ (carbonyl stretching of PEG-OPCB ester), $1180 \mathrm{~cm}^{-1}$ and $1430 \mathrm{~cm}^{-1}$ (C-C \& C=C stretching in fullerene) and $1095 \mathrm{~cm}^{-1}$ (C-O symmetric stretching of PEG) compared to the spectra of pure PCBM and $\mathrm{PEG}_{\sim 15}(\mathrm{OH})_{4}$ (3) (Fig. 2b).

The MALDI-TOF results together with NMR, FTIR and UVvis data confirmed the synthesis of multi-fullerene end-capped PEG dumbbells PEG $_{\sim 4}(\mathrm{OPCB})_{2}(4)$ and stars $\mathrm{PEG}_{\sim 21}(\mathrm{OPCB})_{3}$ (5a) and $\mathrm{PEG}_{\sim 15}(\mathrm{OPCB})_{4}(\mathbf{6 a})$, through the transesterification of PCBM using polydisperse PEGs starting materials. However, the polydispersity, particularly of the tris and tetrakis fullerene products remained problematic. To synthesise monodisperse multi-fullerene end-capped PEG stars, a monodisperse PEG core was required. $\mathrm{PEG}_{24}(\mathrm{OH})_{3}(7)$ was synthesized following a recent procedure; ${ }^{30}$ NMR and MALDI-TOF (see ESI, $\dagger$ Fig. S19, S20 and S21 for ${ }^{1} \mathrm{H},{ }^{13} \mathrm{C}$ NMR and MALDI-TOF spectra of $\left.\mathrm{PEG}_{24}(\mathrm{OH})_{3}(7)\right)$, confirmed the monodisperse nature of the starting material, with a mass of $1247.7 \mathrm{Da}$. This star-shaped PEG, $\mathrm{PEG}_{24}(\mathrm{OH})_{3}(7)$, was then transesterified with PCBM using the same procedure described above for $\operatorname{PEG}_{x}(\mathrm{OH})_{n}$ (1-3). Due to the monodisperse character of $\mathrm{PEG}_{24}(\mathrm{OH})_{3}(7)$, it was possible to separate the resulting monodisperse trisfullerene end-capped PEG, $\mathrm{PEG}_{24}(\mathrm{OPCB})_{3}(\mathbf{8})$ from the mixture 
of mono- and bis-fullerene end-capped $\mathrm{PEG}_{24}(\mathrm{OPCB})_{x}(\mathrm{OH})_{y}$ employing two rounds of column chromatography, followed by three rounds of preparative thin layer chromatography. Since this same purification protocol had failed to isolate the pure materials from the earlier crude product mixtures, it is clear that the monodispersity of the PEG star is helpful in differentiating the products, although the separation is still lengthy.

\section{Monodisperse PEG $_{24}(\mathrm{OPCB})_{3}$}

The MALDI-TOF spectrum of isolated $\mathrm{PEG}_{24}(\mathrm{OPCB})_{3}$ (8) (Fig. 3) showed the expected monoisotopic mass at $3881.82 \mathrm{Da}$, close to the calculated value of 3881.91 Da (Fig. 3D*). The mass spectrometric results were further supported by the ${ }^{1} \mathrm{H}$ NMR spectrum which displayed a new triplet signal corresponding to the acyloxymethylene protons $\left(-\mathrm{CH}_{2}-\mathrm{O}-\mathrm{C}=\mathrm{O}\right)$ adjacent to the newly formed ester carbonyl, at 4.25 ppm (see Fig. 4). The

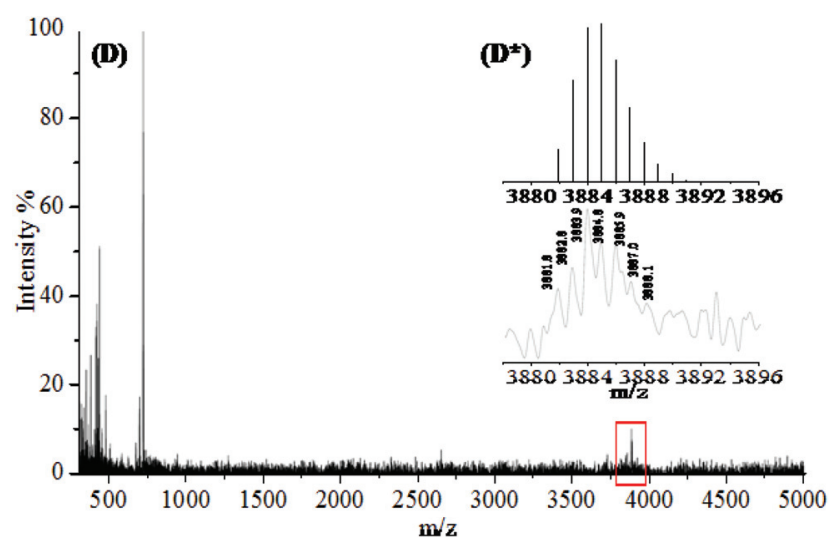

Fig. 3 Experimental and theoretical MALDI-TOF spectra confirming successful transesterification of PCBM with $\mathrm{PEG}_{24}(\mathrm{OH})_{3}$ (7). Full MALDITOF mass spectrum of $\mathrm{PEG}_{24}(\mathrm{OPCB})_{3}$ (8) (D). Expanded region (represented by rectangle) shows the monoisotopic peak pattern of $\mathrm{PEG}_{24}(\mathrm{OPCB})_{3}(8)$ (bottom $\mathrm{D}^{*}$ ). Theoretically simulated peak pattern (upper $D^{*}$ ) for $\mathrm{PEG}_{24}(\mathrm{OPCB})_{3}$ (8). The signal at $720 \mathrm{~m} / \mathrm{z}$ was attributed to $\mathrm{C}_{60}$ and below $720 \mathrm{~m} / \mathrm{z}$ features predominantly related to matrix DCTB.

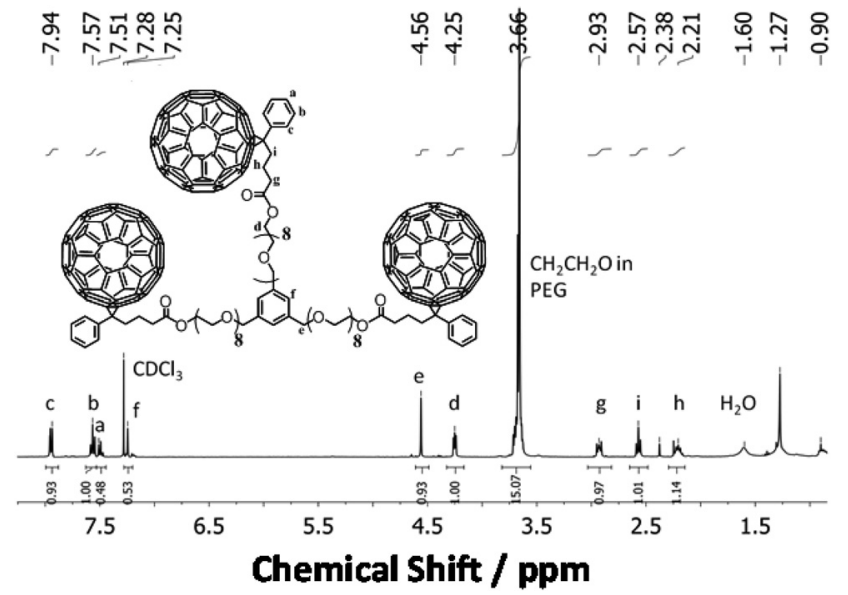

Fig. $4{ }^{1} \mathrm{H}$ NMR spectrum of pure monodisperse $\mathrm{PEG}_{24}(\mathrm{OPCB})_{3}(\mathbf{8})$. Integration of 1 unit $=6 \mathrm{H}$. Trace amounts of water $(1.60 \mathrm{ppm})$ and vacuum grease (1.27 and $0.90 \mathrm{ppm}$ ) were observed. starting material $\mathrm{PEG}_{24}(\mathrm{OH})_{3}(7)$ has three arms, each having eight ethylene oxide repeating units (96 protons in total). After transesterification, one would expect six of 96 protons to be converted into acyloxymethylene protons (d), resolving them from the large backbone resonance. The hydroxyl protons of $\mathrm{PEG}_{24}(\mathrm{OH})_{3}(7)$ at $3.15 \mathrm{ppm}$ (see ESI, $\uparrow$ Fig. S19) disappeared after transesterification, and the integrals ratios of the acyloxymethylene (labelled as d in Fig. 4) to the PEG backbone (labelled as $\mathrm{CH}_{2} \mathrm{CH}_{2} \mathrm{O}$ in Fig. 4) protons was found to be 5.9:90 (consistent with the expected 6:90 for complete acylation). Both MALDI-TOF and ${ }^{1} \mathrm{H}$ NMR analysis provide strong evidence for the successful formation and isolation of the desired monodispersed tris-fullerene substituted $\mathrm{PEG}_{24}(\mathrm{OPCB})_{3}(8)$.

Due to the difficulty in purification, only the fractions containing the desired species were separated and studied closely. During column chromatography a large coloured fraction remained visible in the column. From the analysis of the primary fractions, the remaining materials in the column are likely to be species with lower degrees of substitution. Similar to the preparation of 3-arm adducts of oligothienylenevinylenes and $\mathrm{C}_{60},{ }^{33}$ the yield of isolated $\mathrm{PEG}_{24}(\mathrm{OPCB})_{3}(\mathbf{8})$ and all other adducts were low, even though the reaction medium was saturated with PCBM. ${ }^{29}$ The final yields of fully substituted products were $4 \%$ for $\mathrm{PEG} \sim_{21}(\mathrm{OPCB})_{3} \quad(5), \quad 8 \%$ for $\mathrm{PEG} \sim \sim_{15}(\mathrm{OPCB})_{4}(6)$ and $5 \%$ for $\mathrm{PEG}_{24}(\mathrm{OPCB})_{3}(8)$. In the case of $\mathrm{PEG} \sim{ }_{15}(\mathrm{OPCB})_{4}(6)$, the presence of a minor 3 -arm PEG impurity in the starting material may have affected the overall yield of the reaction. Due to the small yields, elemental analyses were not performed. An initial NMR integration study (Fig. S1 $\dagger$ ) of the $\alpha$-protons (adjacent to newly formed ester) revealed that the reaction proceeded slowly (about 3 days), after which time the catalyst may have become deactivated. Furthermore, although the reaction was carried out at $140{ }^{\circ} \mathrm{C}$, well above the boiling point of methanol, it is possible that the trace amount of methanol released by transesterification may have allowed the reverse reaction to occur to some extent. Finally, although the reaction was kept under nitrogen throughout, the work-up and column chromatography were performed in air. It is well documented that fullerene is a good photo-sensitizer which could easily convert molecular oxygen into singlet oxygen. Fullerene oxidises and/or polymerises in the presence of singlet oxygen, limiting its solubility and that of its adducts. ${ }^{34}$ Therefore, polymerisation of the initially produced fullerene end-capped PEGs during purification may have significantly limited the final purified yield.

\section{Conclusions}

Multiple fullerene end-capped PEGs were synthesized for the first time using single step transesterification of PCBM with PEGs. The monodisperse nature of $\mathrm{PEG}_{24}(\mathrm{OH})_{3}(7)$ allowed isolation of the pure monodisperse fullerene end-capped PEG star $\mathrm{PEG}_{24}(\mathrm{OPCB})_{3}(8)$ from the crude reaction mixture. Monodisperse PEGs with multiple fullerene arms are attractive for 
$\mathrm{BHJ}$ solar cells. It may be possible to tune the phase segregation and/or self-assembly of the fullerene-grafted PEGs by controlling the length of the starting PEG chains and the number of attached fullerene species, whilst retaining the optoelectronic character of PCBM. The synthetic procedure could be applied to the synthesis of other monodisperse multi-arm species with higher mass fullerenes $\left(\mathrm{C}_{70} / \mathrm{C}_{82}\right)$ as experimental data suggest that higher PV efficiency may be achieved in this way. ${ }^{35}$ Such fullerene adducts are also not necessarily limited to a PEG core. Since the reaction relies on converting the hydroxyl into an ester, any cores with terminal $\mathrm{OH}$ groups could be used. The observed partial fullerene substitution of the 3/4-armed products is likely related to the low reaction yields, though steric effects related to short PEG arms may also have played a role. The reaction yield (and likely degree of substitution) might be increased by adjusting the catalyst system, or by using initial fullerene derivatives bearing a more reactive ester (e.g. pentafluorophenyl ester). Future applications of well-defined multiple fullerene stars are likely to emerge with wider availability of well-characterised monodisperse materials. Fullerene dyads have become a popular topic in PV applications. This synthetic procedure for welldefined fullerene derivatives may offer new opportunities for the future study of multiple fullerenes adducts, especially when a conjugated polymer is employed in the synthesis, in place of PEG.

\section{Acknowledgements}

The authors would like to commemorate the late Dr Joachim H. G. Steinke (1964-2013) for his contribution to this work and to the polymer chemistry field. We acknowledge the EPSRC UK National Mass Spectrometry Service at Swansea and EPSRC research grant EP/G007314/1 and EP/J014974/1. MKB is particularly grateful to the Scientific and Technological Research Council of Turkey (TUBITAK) for post-doctoral research permission.

\section{References}

1 A. Dodabalapur, H. E. Katz, L. Torsi and R. C. Haddon, Science, 1995, 269, 1560-1562.

2 R. C. Haddon, T. Siegrist, R. M. Fleming, P. M. Bridenbaugh and R. A. Laudise, J. Mater. Chem., 1995, 5, 1719-1724.

3 G. Yu, J. Gao, J. C. Hummelen, F. Wudl and A. J. Heeger, Science, 1995, 270, 1789-1791.

4 L. S. Roman, M. R. Andersson, T. Yohannes and O. Inganas, Adv. Mater., 1997, 9, 1164-1168.

5 L. Garlaschelli, D. Pasini and F. Spiaggia, Eur. J. Org. Chem., 2005, 4322-4327.

6 Y. H. Zhu, S. Bahnmueller, C. B. Ching, K. Carpenter, N. S. Hosmane and J. A. Maguire, Tetrahedron Lett., 2003, 44, 5473-5476.
7 M. Carano, C. Corvaja, L. Garlaschelli, M. Maggini, M. Marcaccio, F. Paolucci, D. Pasini, P. P. Righetti, E. Sartori and A. Toffoletti, Eur. J. Org. Chem., 2003, 374-384.

8 M. Svensson, F. L. Zhang, S. C. Veenstra, W. J. H. Verhees, J. C. Hummelen, J. M. Kroon, O. Inganas and M. R. Andersson, Adv. Mater., 2003, 15, 988-991.

9 I. A. Howard, R. Mauer, M. Meister and F. Laquai, J. Am. Chem. Soc., 2010, 132, 14866-14876.

10 C.-H. Hsieh, Y.-J. Cheng, P.-J. Li, C.-H. Chen, M. Dubosc, R.-M. Liang and C.-S. Hsu, J. Am. Chem. Soc., 2010, 132, 4887-4893.

11 G. W. Wang, T. H. Zhang, E. H. Hao, L. J. Jiao, Y. Murata and K. Komatsu, Tetrahedron, 2003, 59, 55-60.

12 M. Reyes-Reyes, K. Kim and D. L. Carroll, Appl. Phys. Lett., 2005, 87, 083506.

13 F. Lincker, P. Bourgun, H. Stoeckli-Evans, I. M. Saez, J. W. Goodby and R. Deschenaux, Chem. Commun., 2010, 46, 7522-7524.

14 H. Xin, G. Ren, F. S. Kim and S. A. Jenekhe, Chem. Mater., 2008, 20, 6199-6207.

15 S. M. Tuladhar, M. Sims, S. A. Choulis, C. B. Nielsen, W. N. George, J. H. G. Steinke, D. D. C. Bradley and J. Nelson, Org. Electron., 2009, 10, 562-567.

16 C. M. Bjorstrom, K. O. Magnusson and E. Moons, Synth. Met., 2005, 152, 109-112.

17 P. W. M. Blom, V. D. Mihailetchi, L. J. A. Koster and D. E. Markov, Adv. Mater., 2007, 19, 1551-1566.

18 M. Campoy-Quiles, T. Ferenczi, T. Agostinelli, P. G. Etchegoin, Y. Kim, T. D. Anthopoulos, P. N. Stavrinou, D. D. C. Bradley and J. Nelson, Nat. Mater., 2008, 7, 158164.

19 H. Hoppe and N. S. Sariciftci, J. Mater. Res., 2004, 19, 19241945.

20 C. Müller, T. A. M. Ferenczi, M. Campoy-Quiles, J. M. Frost, D. D. C. Bradley, P. Smith, N. StingelinStutzmann and J. Nelson, Adv. Mater., 2008, 20, 35103515.

21 J. W. Jung, J. W. Jo and W. H. Jo, Adv. Mater., 2011, 23, 1782-1787.

22 J.-Y. Jeng, M.-W. Lin, Y.-J. Hsu, T.-C. Wen and T.-F. Guo, Adv. Energy Mater., 2011, 1, 1192-1198.

23 Q. Tai, J. Li, Z. Liu, Z. Sun, X. Zhao and F. Yan, J. Mater. Chem., 2011, 21, 6848-6853.

24 T. Song, S. H. Goh and S. Y. Lee, Polymer, 2003, 44, 25632567.

25 D. Taton, S. Angot, Y. Gnanou, E. Wolert, S. Setz and R. Duran, Macromolecules, 1998, 31, 6030-6033.

26 H. C. Yau, M. K. Bayazit, J. H. G. Steinke and M. S. P. Shaffer, Macromolecules, 2014, 47, 4870-4875.

27 M. Graetzel, R. A. J. Janssen, D. B. Mitzi and E. H. Sargent, Nature, 2012, 488, 304-312.

28 Q. Wei, T. Nishizawa, K. Tajima and K. Hashimoto, Adv. Mater., 2008, 20, 2211-2216.

29 J. C. Hummelen, F. B. Kooistra and D. F. Kronholm, USPATENT, US2005245606, 2005. 
30 G. Szekely, M. Schaepertoens, P. R. J. Gaffney and A. G. Livingston, Polym. Chem., 2014, 5, 694-697.

31 M. Tryznowski, K. Tomczyk, Z. Fras, J. Gregorowicz, G. Rokicki, E. Wawrzynska and P. G. Parzuchowski, Macromolecules, 2012, 45, 6819-6829.

32 G. Montaudo, F. Samperi and M. S. Montaudo, Prog. Polym. Sci., 2006, 31, 277-357.
33 C. Martineau, P. Blanchard, D. Rondeau, J. Delaunay and J. Roncali, Adv. Mater., 2002, 14, 283-287.

34 H. Watanabe, E. Matsui, Y. Ishiyama and M. Senna, Tetrahedron Lett., 2007, 48, 8132-8137.

35 X. Meng, W. Zhang, Z. a. Tan, Y. Li, Y. Ma, T. Wang, L. Jiang, C. Shu and C. Wang, Adv. Funct. Mater., 2012, 22, 2187-2193. 